\title{
AVALIAÇÃO DA GESTÃO FISCAL NOS ESTADOS BRASILEIROS: ANÁLISE NO QUINQUÊNIO 2011 A 2015
}

\section{EVALUATION OF THE FISCAL MANAGEMENT IN THE BRAZILIAN STATES: ANALYSIS OF THE FIVE-YEAR PERIOD FROM 2011 TO 2015}

0 trabalho participou do XI Congresso ANPCONT promovido em Belo Horizonte (MG) no período de 3 a 6 de junho de 2017.

\section{RESUMO}

O objetivo deste trabalho consistiu na avaliação da qualidade da Gestão Fiscal dos Estados que compõem a Federação brasileira, abrangendo o período de 2011 a 2015. Adotou-se a Metodologia do Índice FIRJAN de Gestão Fiscal (IFGF), desenvolvido pela Federação das Indústrias do Estado do Rio de Janeiro (FIRJAN) para os municípios brasileiros, porém com algumas adaptações aportadas empiricamente. Tal metodologia mensura a Gestão Fiscal por meio de cinco indicadores - Receita Própria, Gastos com Pessoal, Liquidez, Custo da Dívida e Investimentos. De forma subjacente, foram apresentados rankings entre Estados e regiões com base nos resultados obtidos no índice, buscando identificar os fatores que afetaram decisivamente a gestão fiscal no período analisado. A partir dos dados, os resultados revelaram que $85,2 \%$ dos estados apresentaram Gestão Fiscal em Dificuldade e 7,4\% se encontram em situação Fiscal Crítica, enquanto apenas outros 7,4\% apresentaram Gestão Fiscal classificada como Boa. Entre as regiões, a que obteve os melhores resultados foi a Norte, enquanto a pior média está na Região Sul. A média nacional ficou classificada no conceito C (Gestão em Dificuldade). Os principais fatores que prejudicam a gestão fiscal dos Estados correspondem ao elevado desembolso com juros e amortização da dívida, prejudicando, por conseguinte, a liquidez e comprometendo, consequentemente, a condição financeira dos estados. Além disso, alguns estados não respeitaram os limites impostos pela Lei de Responsabilidade Fiscal (LRF), com relação a gastos com pessoal; constatou-se, ainda, que, quando há um bom gerenciamento do gasto com pessoal, há maiores investimentos governamentais, expandindo sua estrutura de serviços.

Palavras chave: Gestão Fiscal. Indicadores Públicos. Condição Financeira. Estados Brasileiros.

\section{ABSTRACT}

The objective of this work was to evaluate the quality of Fiscal Management of the States that make up the Brazilian Federation, covering the period from 2011 to 2015. It was adopted the methodology FIRJAN Fiscal Management Index (IFGF), developed by FIRJAN for the Brazilian municipalities, but with some empirical adaptations. This methodology measures Fiscal Management through five indicators - Own Revenue, Personnel Expenses, Liquidity, Debt Cost and Investments. In an underlying way, rankings between states and regions were presented based on the results obtained in the index, aiming to identify the factors that decisively affected the fiscal management in the analyzed period. From the data, the results revealed that $85.2 \%$ of the states presented Fiscal Management in Difficulty and $7.4 \%$ were in a Critical fiscal situation, while only $7.4 \%$ presented Fiscal Management classified as Good. Among the regions, the best results were in the North, while the worst average was in the South Region. The national average was classified in the C (Difficult Management) concept. The main factors that undermine the fiscal management of the states correspond to the high disbursement with interest and amortization of the Debt, thus harming Liquidity and thereby compromising the states financial condition. In addition, some states did not respect the limits imposed by the LRF, in relation to personnel expenses; it was also verified that when there is a good management of personnel expenses, there are larger government investments, expanding its service structure.
Walter Luiz Leite Carvalho de Miranda Bacharel em Ciências Contábeis pela Universidade Federal do Rio Grande do Norte (UFRN). Contato: Rua Senador João Câmara, 453, Centro, Taipu, RN, Brasil. CEP: 59565-000. E-mail: walter_luiz77@hotmail.com.

\section{Ronaldo José Rêgo de Araújo}

Doutorando pelo Programa de Pós Graduação em Ciências Contábeis pela Universidade Federal da Paraíba (PPGCC-UFPB). Contato: Cidade Universitária, João Pessoa, PB, Brasil. CEP: 58.051900. E-mail: ronaldocontabilidade@ymail.com.

\section{Ígor Figueirêdo Leite}

Mestrando pelo Programa de Pós Graduação em Ciências Contábeis da Universidade Federal da Paraíba (PPGCC-UFPB). Contato: Cidade Universitária, João Pessoa, PB, Brasil. CEP: 58.051-900. E-mail: igorfleitee@gmail.com.

\section{Carla Janaína Ferreira Nobre}

Mestra em Ciências Contábeis pela Universidade Federal da Paraíba (UFPB). Contato: Cidade Universitária, João Pessoa, PB, Brasil. CEP 58.051900 E-mail: carlajanainano-bre@gmail.com. 


\section{INTRODUÇÃO}

A Contabilidade tem se consolidado cada vez mais como ferramenta essencial no processo de registro, mensuração, avaliação e controle do patrimônio público. Para Bezerra Filho (2015), o objetivo da Contabilidade Pública consiste em fornecer informações aos usuários sobre os resultados governamentais alcançados, bem como sobre os aspectos de natureza econômica, financeira e orçamentária do patrimônio público, auxiliando no processo decisório dos gestores, na adequada prestação de contas e no suporte ao controle social.

Nessa perspectiva, Lima e Diniz (2016) dizem que o governo tem por objetivo básico atender às necessidades sociais e econômicas da população, por meio do fornecimento de bens e serviços públicos em níveis satisfatórios. Com o objetivo de tornar possível o cumprimento dos objetivos governamentais, a administração pública faz uso de um importante método de planejamento, o orçamento, instrumento capaz de auxiliar o Executivo no desenvolvimento de uma boa gestão pública, mediante o planejamento, programação, execução e controle (GIACOMONI, 2012).

Em aderência aos objetivos governamentais e visando melhor gestão governamental, no Brasil foram criadas leis de forma a orientar os chefes do Poder Executivo a cultivarem uma administração adequada. A primeira delas foi a Lei 4.320/1964, a qual regulamenta as finanças públicas, objetivando o equilíbrio entre receitas e despesas, além de orientar acerca da elaboração, execução e controle do orçamento e de outros demonstrativos contábeis.

Outra lei bastante importante para a Administração Pública é a Lei Complementar $n^{\circ}$. 101/2000, conhecida como Lei de Responsabilidade Fiscal (LRF). Nela constam regras necessárias ao planejamento, transparência e eficiência na gestão dos recursos públicos. Essa norma orienta os gestores na prevenção de riscos e vieses capazes de afetar o equilíbrio financeiro e orçamentário, estabelecendo o cumprimento de metas, impondo limites de gastos e contração de dívidas (BRASIL, 2000).

Para além disso, pode-se afirmar que o advento da LRF trouxe consigo um conceito importante chamado Accountability, definido por Rocha (2011) como sendo processos de avaliação e responsabilização permanente dos agentes públicos que permitem aos cidadãos o controle do poder governamental concedido aos seus representantes.

Dessa forma, para que os governos atinjam seus objetivos, é necessário arrecadar recursos. Sobre o assunto, de acordo com o Instituto Brasileiro de Planejamento e Tributação (IBPT, 2014), o Governo brasileiro bate recordes em arrecadação, chegando a representar, em 2014, 35,42\% do PIB. Ainda de acordo com o órgão (2014), 65\% desse montante corresponde a tributos federais, $28,47 \%$ a tributos estaduais e apenas 5,58\% a tributos municipais. Esses dados demonstram tanto as dificuldades arrecadatórias dos estados e municípios quanto a divisão desigual do pacto federativo.

Buscando suprir a insuficiência de receita dos entes federativos que arrecadam menos, além de a Constituição Federal, em seus artigos 157 e 158, garantir a repartição das receitas tributárias, no Art.159, legisla sobre as transferências governamentais, em que a União fará repasses aos demais entes federativos por meio dos Fundos de Participação dos Estados e dos Municípios (BRASIL, 1988), ajudando financeira e orçamentariamente os entes federados que não conseguem arrecadar mais recursos.

Além da geração de receitas, os governos necessitarão assumir despesas para atingir seus planos, metas e objetivos, como folha de pagamento e investimentos na condução das políticas públicas em geral. Entretanto, um problema que tem impactado diretamente as finanças públicas consiste no crescimento desordenado das despesas ou em montantes superiores aos das receitas, desequilibrando os orçamentos governamentais. Giacomoni (2012) cita um estudo feito por Musgrave sobre o desempenho das despesas públicas, no qual aponta algumas das principais variáveis que contribuem de forma direta para que o gasto seja alterado, são elas: crescimento de renda per capita e o aumento da demanda por bens e serviços públicos; mudanças tecnológicas; mudanças populacionais; e custos relevantes dos serviços públicos sensíveis à inflação.

Em se tratando do desempenho e eficiência no gasto público, Ribeiro (2008) destaca que o Brasil tem apresentado um resultado insatisfatório e abaixo da média dos países da América Latina em termos de eficiência na aplicação dos recursos públicos. Uma análise sobre a equidade e eficiência dos estados brasileiros demonstrou que a Região Sul do país apresentou a melhor disponibilidade de serviços e a maior eficiência no uso dos recursos, enquanto no caminho oposto encontra-se a Região Nordeste, onde há forte carência e grande desperdício de recursos públicos (SOUZA JUNIOR E GASPARINI, 2006).

Dessa forma, não bastasse o crescimento elevado das despesas, outro fator agravante nas contas públicas é o desperdício excessivo de recursos financeiros, resultando na baixa qualidade dos serviços essenciais para a sociedade, como educação, saúde e segurança, assim como impactando de forma negativa a economia e o desenvolvimento do país.

Outro desafio para a Administração Pública no país é a Dívida Pública. De acordo com a Secretaria do Tesouro Nacional (2016), o total da dívida pública federal é de R \$2,9 trilhões. Assim como a União, outras esferas administrativas vêm sofrendo com o desequilíbrio de suas finanças. Nos estados, o risco de insolvência é muito maior, devido à alta dívida com a União. Sob outro aspecto, um estudo feito pelo Ministério da Fazenda (2016) mostra que a folha de pagamento em todos os estados cresceu 97,28\% nos últimos sete anos - chegando a R $\$ 238,4$ bilhões em 2015. No mesmo período, o custo da dívida com a União cresceu 71,05\% - totalizando R\$ 54 bilhões.

Buscando um alívio financeiro para os estados, aprovou-se a Lei Complementar 156/2016, de 28 de dezembro de 2016, a qual estabelece um plano de auxílio e medidas para estimular o reequilíbrio fiscal, alongando as dívidas estaduais por mais 30 anos e suspendendo até o fim de 2016 o pagamento das parcelas. Outro importante marco foi a aprovação 
da Emenda Constitucional 95/2016, que se tornou bastante polêmica ao propor um 'congelamento de gastos' com relação ao ano anterior atualizados à inflação, durante um período de 20 anos. A medida irá valer para todas as esferas administrativas, e é considerada por seus defensores como uma medida de reequilíbrio das contas públicas e retomada do crescimento econômico (BRASIL, 2016). Todos esses dispositivos foram criados diante das péssimas situações das gestões nos últimos anos, sobretudo as estaduais.

Como meio de diagnosticar a situação da administração pública, são utilizados indicadores contábeis, financeiros, de desenvolvimento ou de resultado, que são capazes de medir o efeito das ações e políticas públicas voltadas para diversas áreas (AZEVEDO, 2016). Dessa forma, visando estimular a responsabilidade administrativa e aprimorar a gestão fiscal dos municípios, a Federação das Indústrias do Estado do Rio de Janeiro (FIRJAN) desenvolveu o Índice FIRJAN de Gestão Fiscal (IFGF), metodologia utilizada para verificar a situação das gestões municipais, que busca assinalar como estão sendo tomadas as decisões dos gestores na alocação adequada dos recursos públicos, além de avaliar de forma qualitativa a gestão fiscal praticada pelo Poder Executivo local (FIRJAN, 2016).

Na busca pela identificação da situação fiscal dos Estados brasileiros, Costa (2016) utilizou o modelo estatístico do Government Finance Statistics Manual - 2014 (GFSM-2014) proposto pelo Fundo Monetário Internacional, sugerindo que a capacidade de realizar investimentos com recursos próprios pelos estados brasileiros vem reduzindo ano após ano, e que há uma necessidade muito grande por parte dos estados em reduzir gastos, principalmente com Pessoal e Encargos Sociais.

Dadas essas considerações, este trabalho está orientado pela seguinte questão problema: Qual a situação da Gestão Fiscal dos Estados Brasileiros no quinquênio 2011-2015?

Embora haja discussões acerca da gestão fiscal dos estados brasileiros (COSTA, 2016; SOUZA JUNIOR e GASPARINI, 2006) e sobre como quantificar a qualidade da responsabilidade fiscal, tão discutida e exigida pela LRF (COSTA, 2016), assim como estudos que identificam fatores que possam caracterizar a gestão fiscal dos municípios (SENA, 2012), não foram identificadas pesquisas que buscassem avaliar a responsabilidade na gestão fiscal dos estados brasileiros, assim como identificar os condicionadores observáveis nessa gestão. Dessa forma, este estudo objetiva analisar a situação da Gestão Fiscal dos Estados Brasileiros no quinquênio 2011-2015.

Além desta introdução, este artigo está estruturado com outros capítulos que abordam: os fundamentos teóricos que circundam a gestão fiscal governamental, a apresentação dos procedimentos metodológicos para o alcance do objetivo fixado, seguidos dos resultados e análises resultantes da metodologia adotada. Além de apresentar as considerações resultantes deste estudo.

\section{FUNDAMENTAÇÃO TEÓRICA 2.1 Responsabilidade fiscal}

Desenvolver a responsabilidade fiscal na vasta e abrangente área de atuação governamental possibilita um bom direcionamento para o Poder Executivo conduzir suas ações anteriormente planejadas (LIMA; DINIZ, 2016). Sancionada em 4 de maio de 2000, a Lei de Responsabilidade na Gestão Fiscal pode ser considerada um marco na história da Administração Pública Brasileira, por se tratar de um instrumento para conter déficits públicos e o endividamento crescente dos entes federativos. Entretanto, ela não se restringe apenas a impor limites ao gasto com pessoal e endividamento, mas também contempla o orçamento como um todo ao definir diretrizes para a sua elaboração, execução e controle, além de promover a transparência nas contas públicas ao exigir relatórios e demonstrativos fiscais, o que a torna o instrumento de controle fiscal mais abrangente já instituído no país (GIUBERTI, 2005). Para Araújo, Santos Filho e Gomes (2015), a LRF foi um marco no controle institucional brasileiro e no processo de planejamento governamental, em virtude das diversas ferramentas que trouxe para a administração pública.

Para Dalmonech, Teixeira, Sant'ana (2011), o propósito da criação da LRF era estabelecer a simetria informacional, com obrigatoriedade de publicações de relatórios governamentais e desenvolvimento de ações planejadas e transparentes, e estabelecer uma relação entre as despesas e as receitas buscando alcançar o equilíbrio das contas públicas, em que os gestores se responsabilizam pela adequada prestação de contas, sob risco de punições cabíveis. Objetivando alcançar a melhoria da gestão e da qualidade do serviço público, na visão de Sousa (2008), a LRF resgatou o orçamento público como peça de planejamento e controle, e introduziu progressos importantes no processo orçamentário, reforçando o papel da LDO como instrumento de imposição de equilíbrio fiscal.

A LRF reforçou medidas adotadas anteriormente e promoveu uma mudança institucional e cultural no uso adequado do dinheiro público, para que os recursos arrecadados sejam aplicados no atendimento das necessidades da sociedade, promovendo a transparência dos gastos públicos com a atuação direta da sociedade estimulando o controle social, além de inserir mudanças na contabilidade aplicada ao setor público e na execução do orçamento público, na medida em que introduziu diversos limites de gastos, cujo objetivo maior é melhorar a administração das contas públicas no Brasil, principalmente no que se refere ao endividamento (SALGUEIRO; MELO; SILVA, 2012). Diante disso, a transparência é um dos pontos mais importantes da LRF, pois visa um nível de fiscalização maior por parte das instituições competentes e da sociedade em relação aos atos praticados no curso da gestão dos gastos públicos (SALES; MARTINS, 2014). 


\subsubsection{Controle dos gastos com pessoal}

O gasto com Pessoal do Poder Executivo é a maior despesa corrente governamental, segundo GIUBERTI (2005); entre 1996 e 2000 os gastos desse item nos Estados se mantiveram na média de 67\% da RCL no intuito de controlar essa maior parcela que consume os recursos públicos; em seu Art. 19, inciso II, a LRF estabelece para os Estados o limite de $60 \%$ da Receita Corrente Líquida (RCL) para os gastos com pessoal e demais encargos relativos a este. No Art.20, inciso II, a repartição dos limites globais para os Estados e Distrito Federal foi estabelecida em: 49\% para o Poder Executivo, 6\% para o Judiciário, 3\% para o Legislativo e Tribunal de Contas do Estado e 2\% para o Ministério Público Estadual (BRASIL, 2000).

Nakaguma e Bender (2006) afirmam que, nos dois primeiros anos, a LRF contribuiu para a diminuição expressiva das despesas de custeio, devido aos limites impostos para o gasto com pessoal; de acordo com a pesquisa, a redução das despesas totais foi de $8,4 \%$, enquanto o total de gastos com pessoal obteve uma redução de cerca de $20 \%$.

Para Teixeira (2010), entre os anos de 2000 e 2006, a LRF conseguiu cumprir sua meta, que era equilibrar a Despesa Líquida com Pessoal do Executivo com relação à Receita Corrente Líquida (RCL), mas essas variações não foram suficientes para proporcionar diferenças tão significativas. O estudo de Correia (2014) mostrou que em 2007, quanto maior a dívida, maior era o gasto com pessoal e os encargos sociais, porém a partir de 2011 essa relação de casualidade passa a perder a força. O autor complementa que até 2007, quanto maior o gasto com pessoal e encargos sociais, maiores eram o pagamento de juros e amortização da dívida, já em 2011 essa relação muda, de modo que, quanto maior o gasto com pessoal e encargos sociais, menor seria o pagamento de juros e amortização da dívida.

Conforme Giuberti (2005), gastos elevados com o funcionalismo público reduzem a receita disponível para fornecer serviços públicos básicos e para investir, em especial, no item infraestrutura; logo, pode-se afirmar que ao reduzir gastos com pessoal, o Estado terá à disposição mais recursos para realizar investimentos e aplicar em áreas essenciais como segurança, saúde e educação.

Dadas essas considerações, surge a seguinte hipótese de pesquisa:

H1: Entes Governamentais que apresentam menores gastos com pessoal conseguem realizar mais investimentos.

\subsubsection{Controle da dívida pública e das operações de crédito}

Na concepção de Silva, Carvalho e Medeiros (2009), o endividamento público, se bem administrado, permite ampliar o bem-estar da sociedade e o bom funcionamento da economia, possibilitando, também, atender a despesas emergenciais e assegurar o financiamento tempestivo de grandes projetos com horizonte de retorno no médio e no longo prazos. O endividamento público pode exercer funções ainda mais amplas para o bom funcionamento da economia, auxiliando a condução da política monetária e favorecendo a consolidação do sistema financeiro. Segundo Costa (2017) a efetividade da LRF depende do período e da amostra utilizada, já que os limites padronizados nem sempre estão de acordo com a realidade dos municípios. Ainda, conforme Costa (2017), os municípios de maiores populações estavam acima do limite de endividamento e a LRF incentivou a redução da dívida e o oposto acontece nas cidades com menores populações que estão abaixo do nível e possuem uma folga para atingir o limite.

Contudo, Lima e Diniz (2016) dizem que o elevado comprometimento do orçamento público com a dívida pode reduzir a capacidade do governo em conseguir bons resultados para a população, tendo em vista que sobrará pouca folga orçamentária para destinar a outras políticas governamentais.

Diante dessas considerações, esta pesquisa estabelece a segunda hipótese:

H2: Entes governamentais com bons níveis de endividamento apresentam bons índices fiscais.

No Brasil, o endividamento no Setor Público é um problema existente em todas as esferas governamentais desde muito tempo. A Secretaria do Tesouro Nacional, por meio do Relatório Anual da Dívida Pública - 2015, afirmou que o montante da Dívida Pública Federal foi de R $\$ 2.793,00$ bilhões ao fim do exercício.

\subsubsection{Controle de liquidez e restos a pagar}

Ao final de cada exercício, as despesas orçamentárias empenhadas e não pagas poderão ter sua inscrição na dívida flutuante (curto prazo). De acordo com o Manual de Contabilidade Aplicada ao Setor Público (MCASP), em sua $6^{a}$ edição, existem dois tipos de restos a pagar, são eles: os processados e os não processados. Serão classificadas como restos a pagar processados as despesas orçamentárias que transitaram pelas fases de empenho e liquidação, em que o ente fornecedor/prestador cumpriu com sua obrigação, garantindo o seu direito líquido e certo de recebimento, restando apenas o último estágio de pagamento (desembolso); enquanto os restos a pagar não processados são as despesas orçamentárias apenas empenhadas, mas não liquidadas. Segundo Silva e Lima (2016), o crescente aumento de restos a pagar nas contas públicas nacionais tem gerado inúmeros transtornos para a regular execução do orçamento, pois a dívida pendente de pagamento deixada pelo governo afeta distintos setores das finanças públicas brasileiras.

Como forma de garantir a Liquidez financeira no curto prazo e o não comprometimento de caixa nos períodos 
posteriores, o art.42 estabelece a vedação ao chefe do Poder Executivo, nos últimos dois quadrimestres do seu mandato, de contrair obrigação de despesa que não possa ser cumprida integralmente dentro dele, ou que tenha parcelas a serem pagas no exercício seguinte sem que haja suficiente disponibilidade de caixa para este efeito. Dessa forma, evita-se que no último ano de mandato o titular do Poder Executivo entregue o cargo e deixe dívidas no curto prazo sem a quantidade suficiente de disponibilidades para honrar com as obrigações, prejudicando, assim, a gestão do seu sucessor.

\subsection{Condição financeira governamental}

Os órgãos da administração direta e as entidades da administração indireta que compõem o governo têm por objetivo básico satisfazer as necessidades sociais e econômicas da população, fornecendo bens e serviços públicos a um nível satisfatório de qualidade nas diversas funções de governo: saúde, saneamento, lazer, educação, assistência social, segurança, entre outras (LIMA; DINIZ, 2016).

Para que seja possível realizar suas funções consideradas essenciais, é imprescindível que o Governo tenha uma condição financeira estável, equilibrada e saudável. Lima e Diniz (2016) afirmam que manter a saúde financeira de um ente federativo constitui importante requisito para o fornecimento satisfatório e contínuo de diferentes tipos de serviços públicos a fim de satisfazer as necessidades da população e garantir o sentimento de bem-estar social.

Condição Financeira Governamental pode ser definida segundo Groves e Valente (2003) como sendo uma capacidade dos governos locais em financiar seus serviços em uma base contínua.

A análise da condição financeira vai além da observância apenas dos recursos econômicos e estrutura financeira. Também se exige verificar aspectos extracontábeis, por exemplo, situação social e econômica de uma localidade, demografia, taxa de analfabetismo, violência, aspectos climáticos e renda per capita, pois, segundo a Teoria da Condição Financeira, os fatores externos e internos à organização influenciam na sua condição financeira, e vice-versa (LIMA; DINIZ, 2016).

Também se faz necessária a realização da análise da condição financeira sob as perspectivas das receitas e das despesas por parte do governo, pois, conforme Lima e Diniz (2016), analisar a condição financeira sob a ótica da receita possibilita ao governo enxergar sua real capacidade de fornecer bens e serviços à comunidade de maneira contínua, frente as suas principais fontes de recursos, que são a arrecadação tributária e as transferências governamentais (em se tratando de Estados e Municípios). Enquanto a análise da condição financeira sob a ótica da despesa permite avaliar o grau de pressão por gastos, que corresponde ao atendimento das necessidades da comunidade.

\subsection{Estudos anteriores}

Entre os principais estudos que envolvem a temática vertebral deste trabalho, alguns se relacionam diretamente quanto à metodologia aplicada (IFGF), objeto de estudo (Gestão Fiscal) e Amostra/População (Estados da Federação), e estão apresentados no Quadro 1.

Quadro 1 - Detalhamento dos estudos que evidenciaram nuances da Gestão Fiscal Governamental

\begin{tabular}{|c|c|c|}
\hline Título & $\begin{array}{l}\text { Autor } \\
\text { (Ano) }\end{array}$ & Principais resultados \\
\hline $\begin{array}{l}\text { CONTRIBUIÇÃO À METO- } \\
\text { DOLOGIA DE APURAÇÃO } \\
\text { DO RESULTADO FISCAL } \\
\text { NOS ESTADOS BRASILEI- } \\
\text { ROS: um estudo empírico de } \\
2008 \text { a } 2015\end{array}$ & $\begin{array}{l}\text { COSTA } \\
(2016)\end{array}$ & $\begin{array}{l}\text { Constatou-se que houve uma menor variação da Receita Tributária e maior nas de } \\
\text { Transferências Intergovernamentais; e que a margem financeira para realizar inves- } \\
\text { timentos com recursos próprios ou obter superávits tem apresentado redução, ano } \\
\text { após ano, surgindo também a necessidade de redução de gastos no âmbito dos esta- } \\
\text { dos como um todo. }\end{array}$ \\
\hline $\begin{array}{l}\text { Análise da equidade e da } \\
\text { eficiência dos estados no } \\
\text { contexto do federalismo } \\
\text { fiscal brasileiro }\end{array}$ & $\begin{array}{l}\text { SOUZA } \\
\text { JUNIOR E } \\
\text { GASPARI- } \\
\text { NI (2006) }\end{array}$ & $\begin{array}{l}\text { Os resultados mostram que a região Sul apresentou a melhor disponibilidade de } \\
\text { serviços e a maior eficiência no uso dos recursos. No extremo oposto encontra-se o } \\
\text { Nordeste, onde há fortes carências e também grande desperdício. Quanto ao esforço } \\
\text { de arrecadação, não se evidenciaram perdas tributárias acentuadas. O estudo conclu } \\
\text { que todos os Estados necessitam de complementação de verbas, mas constata distor } \\
\text { ções presentes no atual critério. }\end{array}$ \\
\hline $\begin{array}{l}\text { ÍNDICE DE GESTÃO } \\
\text { FISCAL DOS MUNICÍPIOS: } \\
\text { Análise do IGF de Vinte } \\
\text { Municípios do RN no } \\
\text { Exercício } 2010\end{array}$ & $\begin{array}{l}\text { SENA } \\
(2012)\end{array}$ & $\begin{array}{l}\text { Identificou-se que não existe relação direta entre os melhores resultados com o porte } \\
\text { dos municípios. Quanto à classificação, nenhuma cidade apresentou gestão de exce- } \\
\text { lência, e } 90 \% \text { delas apresentaram gestão fiscal difícil ou crítica. }\end{array}$ \\
\hline
\end{tabular}

Fonte: Elaborado pelos autores (2017).

Embora os trabalhos citados anteriormente tenham se debruçado a identificar a responsabilidade fiscal das entidades governamentais e, em especial, o de Costa, Araújo, Alves e Santos (2016), que propuseram o cálculo do indicador de gestão fiscal para os estados brasileiros, mas não se detiveram a calculá-lo efetivamente, motivo pelo qual este trabalho buscou calcular o indicador considerando os últimos anos. 


\section{PROCEDIMENTOS METODOLÓGICOS 3.1 Caracterização da pesquisa}

Este estudo configura-se, quanto aos objetivos, como pesquisa descritiva e explicativa, pois haverá um cunho descritivo na busca por identificar as características fiscais de determinados Estados e regiões, além de buscar verificar relações entre as variáveis calculadas (BEUREN, 2008). Seu caráter explicativo consiste na busca por responder quais os principais fatores que afetam o equilíbrio das contas públicas dos entes federativos subnacionais.

Já com relação aos procedimentos, classifica-se como pesquisa bibliográfica e documental. E quanto à abordagem do problema, compreende a pesquisa qualitativa e quantitativa, porque serão aplicados instrumentos de cálculos estatísticos, tanto na coleta quanto no tratamento de dados, assim como por mensurar qualitativamente a situação fiscal das entidades federativas estudadas (BEUREN, 2008).

Em se tratando do universo, este corresponde aos 26 Estados da Federação brasileira e o Distrito Federal. Uma vez que este estudo abrangerá todos eles, satisfaz, portanto, a ideia de censo dos estados da República Federativa do Brasil.

No que se refere à sua abrangência, corresponde ao quinquênio entre 2011 e 2015, por ser o período mais recente em termos de dados disponíveis e suficientes para captar a situação fiscal dos estados brasileiros.

\subsection{Coleta e tratamento dos dados}

A coleta foi realizada por meio da base de dados Finanças do Brasil - FINBRA da Secretaria do Tesouro Nacional. Os dados não identificados nessa plataforma foram acessados por meio de consultas nos websites oficiais: Portal Compara Brasil; Portais da Transparência do Estado do Ceará, da Paraíba, do Tocantins; Controladoria Geral do Estado do Rio Grande do Norte, do Governo do Maranhão e do Mato Grosso do Sul, que são responsáveis pela divulgação de informações contábeis referentes às Entidades Governamentais.

\subsection{Descrição e interpretação das variáveis de pesquisa}

De acordo com a FIRJAN (2015), o IFGF é composto por 5 indicadores, que são: Receita Própria, Gastos com Pessoal, Liquidez, Investimentos e Custo da Dívida, os quais serão detalhados na sequência.

O IFGF Receita Própria foi construído com base no pressuposto de que o ente Federativo seja capaz de gerar receitas próprias em, pelo menos, metade de suas receitas correntes líquidas. Assim, os entes que não geram receita própria recebem 0,00 e os entes que geram $50 \%$ da RCL ou mais recebem 1,00 no IFGF Receita Própria; os demais resultados são escalonados entre esses dois pontos.

Já o IFGF Gastos com Pessoal busca medir o quanto da receita do governo está sendo destinada à despesa com pessoal. A importância desse índice é que o gasto com pessoal é um componente substancial nos orçamentos governamentais. Na leitura dos resultados, quanto mais próximo de 1,00, menor o comprometimento do orçamento com a folha de salários do funcionalismo local e, consequentemente, maior discricionariedade para o Governo executar suas políticas públicas no atendimento às necessidades da população.

O indicador IFGF Liquidez mantém o princípio de verificar se os Governos estão postergando pagamentos de despesas para o exercício seguinte sem deixar recursos suficientes para cobri-los. Na leitura dos resultados, quanto mais próximo de 1,00, menos o Governo está postergando pagamentos para o exercício seguinte sem a devida cobertura.

Um dos maiores desafios enfrentados pelos Estados da Federação é a Dívida (BRASIL, 2016), dessa forma, IFGF Custo da Dívida avalia o peso dos encargos da dívida em relação às receitas líquidas reais. Os resultados sugerem que quanto mais próximo de 1,00, menor o comprometimento dos recursos do Governo com juros e amortizações referentes a empréstimos contraídos em anos anteriores.

Por fim, o IFGF Investimentos possibilita mensurar a parcela dos investimentos nos orçamentos municipais, estabelecendo uma nota de corte para este indicador: para os entes que investiram mais de $20 \%$ da sua RCL foi atribuída nota 1,00. Na leitura dos resultados, quanto mais próximo de 1,00, mais investimentos foram realizados pelos Governos.

A fórmula de cada índice e a síntese dos objetivos dos cinco indicadores estão apresentadas no Quadro 2.

Na operacionalização desses índices, a FIRJAN (2016) atribui peso 22,5\% para cada indicador, exceto para o Custo da Dívida, ao qual atribui 10\%, justificado pelo fato de os Municípios possuírem um baixo endividamento. Contudo, Costa (2016) constatou que a margem financeira para os Estados realizarem investimentos com recursos próprios ou obter superávits tem apresentado redução acentuada ano após ano. Além disso, como se sabe que os Estados vêm sofrendo consideravelmente com a dívida, adaptou-se a metodologia Firjan atribuindo peso de 22,5\% para o Custo da Dívida e de $10 \%$ para os Investimentos, conforme apresentado na Equação 1.

$$
\mathrm{IFGF}_{\mathrm{it}}=\left\{\left(\mathrm{IFGF} \mathrm{RP}_{\mathrm{it}}+\mathrm{IFGF} \mathrm{GP}_{\mathrm{it}}+\mathrm{IFGF} \mathrm{L}_{\mathrm{it}}+\mathrm{IFGF} \mathrm{CD}_{\mathrm{it}}\right) \times 22,5 \%\right\}+\mathrm{IFGF}_{\mathrm{it}} \times 10 \% \text { (Equação 1) }
$$


Quadro 2 - Composição da base de cálculo para formação do IFGF Estados brasileiros

\begin{tabular}{|c|c|c|}
\hline SIGLA & ÍNDICE & OBJETIVO \\
\hline $\begin{array}{l}\text { IFGF } \\
\text { RecProp }\end{array}$ & $\begin{array}{l}\text { IFGF Receita Própria }=(\text { Receita Pró- } \\
\text { pria / Receita Corrente Líquida) }\end{array}$ & Verificar o grau de autonomia das receitas do Ente Federativo \\
\hline IFGF GPess & $\begin{array}{c}\text { IFGF Gasto com Pessoal }=1 \text { - (Gasto } \\
\text { com pessoal / Receita Corrente Lí- } \\
\text { quida) }\end{array}$ & $\begin{array}{l}\text { Avaliar o comprometimento das receitas com as despesas de pes- } \\
\text { soal. }\end{array}$ \\
\hline IFGF Liquidez & $\begin{array}{c}\text { IFGF Liquidez }=\text { (Caixa - Obrigações } \\
\text { em Circulação / Receita Corrente } \\
\text { Líquida })\end{array}$ & $\begin{array}{l}\text { O princípio de verificar se os Governos estão postergando paga- } \\
\text { mentos de despesas para o exercício seguinte sem deixar recursos } \\
\text { suficientes para cobri-los. }\end{array}$ \\
\hline IFGF CustDívida & $\begin{array}{l}\text { IFGF Custo da Dívida = (Juros e Amor- } \\
\text { tizações / Receita Corrente Líquida) }\end{array}$ & $\begin{array}{c}\text { Avaliar o comprometimento do orçamento com encargos da dívida } \\
\text { em relação às receitas líquidas reais. }\end{array}$ \\
\hline IFGF Investim & $\begin{array}{l}\text { IFGF Investimentos = (Investimento / } \\
\text { Receita Corrente Líquida) }\end{array}$ & Avaliar o total de investimentos em relação à receita. \\
\hline
\end{tabular}

Fonte: FIRJAN (2017) - Adaptado.

Dessa forma, para obter o IFGF geral do quinquênio, o cálculo será a média aritmética simples, que corresponde à soma de todos os índices anuais, divididos pela quantidade de anos analisados, como demonstra a Equação 2.

$$
\text { IFGFgeral }_{\mathrm{i}}=\frac{\mathrm{IFGF}_{2011}+\mathrm{IFGF}_{2012}+\mathrm{IFGF}_{2013}+\mathrm{IFGF}_{2014}+\mathrm{IFGF}_{2015}+}{5} \quad \text { (Equação 2) }
$$

Com relação à interpretação, a FIRJAN (2015) estabelece 4 tipos de conceitos para avaliar a Gestão Fiscal do Poder Executivo. O conceito será definido conforme a faixa em que se encontra o resultado que foi obtido pelo ente Federativo, e que é interpretado conforme a Tabela 1.

Tabela 1 - Conceitos sobre a Qualidade da Gestão Fiscal

\begin{tabular}{ccc}
\hline Conceito & Resultado & Avaliação/Interpretação \\
\hline A & Acima de 0,8001 & Gestão de Excelência \\
B & Entre 0,6001 e 0,8 & Boa Gestão \\
C & Entre 0,4001 e 0,6 & Gestão em Dificuldade \\
D & Inferior a 0,4 & Gestão Crítica \\
\hline
\end{tabular}

Fonte: Anexo Metodológico - FIRJAN (2015).

Além disso, de forma a testar as hipóteses de pesquisa estabelecidas, serão calculadas correlações bivariadas entre as variáveis trabalhadas neste estudo, de modo a verificar as seguintes hipóteses:

H1: Entes Governamentais que apresentam menores gastos com pessoal conseguem realizar mais investimentos.

H2: Entes governamentais que apresentam dívidas boas apresentam bons índices fiscais.

Para isto, serão verificadas as correlações apresentadas entre as variáveis: Gasto com Pessoal e o IFGF Geral; Custo da Dívida e IFGF Geral; e Custo da Dívida e Liquidez.

Para tanto, consideram-se dívidas boas aquelas que não desequilibram a situação orçamentária, assim como não comprometem a liquidez da entidade e proporcionam resultados satisfatórios para a entidade como um todo. O indicador IFGF Custo da Dívida irá exprimir uma dívida boa quanto mais próximo for de 1,00. 


\section{RESULTADOS E ANÁLISE}

A Tabela 2 apresenta os indicadores médios de cada índice do IFGF dos estados brasileiros, assim como a base de cálculo de cada indicador que compõe o IFGF.

Tabela 2 - Descrição dos resultados da base de cálculo do IFGF dos Estados brasileiros, considerando o período de 2011 a 2015

\begin{tabular}{ccccccc}
\hline IFGF & $\mathbf{2 0 1 1}$ & $\mathbf{2 0 1 2}$ & $\mathbf{2 0 1 3}$ & $\mathbf{2 0 1 4}$ & $\mathbf{2 0 1 5}$ & Média \\
\hline Receita Própria & 0,94 & 0,96 & 0,96 & 0,97 & 0,96 & 0,96 \\
Gastos com Pessoal & 0,59 & 0,56 & 0,55 & 0,57 & 0,50 & 0,56 \\
Liquidez & 0,18 & 0,23 & 0,26 & 0,19 & 0,20 & 0,21 \\
Custo da Dívida & 0,31 & 0,30 & 0,30 & 0,40 & 0,35 & 0,33 \\
Investimentos & 0,44 & 0,42 & 0,52 & 0,60 & 0,36 & 0,47 \\
IFGF Geral & 0,50 & 0,50 & 0,52 & 0,54 & 0,49 & 0,51 \\
\hline
\end{tabular}

Fonte: Elaborado pelos autores (2017).

De forma geral, percebe-se que o indicador Receita Própria foi o que apresentou os melhores resultados entre os cinco indicadores que compõem o índice. O IFGF Receita Própria se manteve alto em todos os anos, e obteve uma média de 0,96, sugerindo que a maioria dos Estados Brasileiros possuem esforços arrecadatórios próprios, não apresentando diferenças significativas de um estado para outro, conforme evidenciado por Souza Junior e Gasparini (2006) e Costa (2016), sendo, por sua vez, um aspecto positivo para a gestão fiscal governamental.

O segundo indicador avalia o nível de comprometimento do orçamento com relação ao pagamento de salários e encargos sociais referente à folha do funcionalismo público. Durante todo o período analisado, a média de todos os Estados quanto ao IFGF Gastos com Pessoal se encontrou abaixo de 0,6001, classificando-se no Conceito C (Gestão em Dificuldade), demonstrando que os gastos com pessoal comprometem grande parte dos orçamentos desses entes federativos, que acabam por prejudicar sua condição financeira, conforme Lima e Diniz (2016).

O indicador de Liquidez demonstra que, ao final dos exercícios, os Estados mantiveram em caixa recursos financeiros suficientes para cobrir os Restos a Pagar do exercício seguinte, como bem determina a LRF em seu Art. 42. Com isso, o IFGF Liquidez foi o índice que apresentou os piores resultados, demonstrando que, nos cinco anos analisados, o índice obteve médias muito baixas, em que a média geral encontrada foi de 0,21 , sendo classificada no conceito D (Crítica). Além de esses resultados assinalarem um fator prejudicial à condição financeira governamental dos estados brasileiros, estes confirmam os pressupostos de Costa (2016) de que a margem financeira para realizar investimentos com recursos próprios ou obter superávits tem apresentado redução, ano após ano, resultando em problemas fiscais futuros.

Do mesmo modo, o IFGF Custo da Dívida que avalia a quantidade de juros e amortizações da dívida sobre a RLR, também revelou que, no período analisado, as gestões estaduais foram classificadas no conceito D (Gestão Crítica), prejudicando igualmente a situação fiscal das esferas subnacionais brasileiras, assinalando como um fator negativo a boa condição financeira das entidades governamentais, conforme a Teoria da Condição Financeira (LIMA; DINIZ, 2016).

O último índice buscou mensurar a quantidade de investimentos realizados nos orçamentos Estaduais durante o período. Entre os anos de 2011 e 2015, a média do IFGF Investimentos resultou em conceito C (Gestão em Dificuldade), reduzindo consideravelmente de 0,44 para 0,36 (Gestão Crítica), fruto da crise política e econômica que se instalou no Brasil no final de 2014. Extrai-se, portanto, que esse aspecto também tem sido prejudicial à gestão fiscal dos estados brasileiros, fator já destacado por Costa (2016) quando afirma que investimentos com recursos próprios têm apresentado redução nas esferas governamentais.

Com estes resultados, permite-se afirmar que os estados brasileiros têm conseguido gerar suas receitas próprias, o que os torna responsáveis na gestão fiscal no quesito arrecadação. Contudo, as gestões têm demonstrado dificuldades alocativas desses recursos, apresentando indicadores desfavoráveis na gestão do gasto com pessoal, na dívida e nos investimentos. Além disso, outro aspecto negativo identificado consiste na falta de liquidez governamental, prejudicando as finanças futuras.

Adicionalmente, buscou-se estabelecer uma classificação geral dos Estados, obtidas pela média do IFGF geral abrangendo todos os índices e atribuindo-se a eles os seus respectivos pesos. Demonstrou-se, ainda, a localização de cada Estado em relação ao grupo de referência, considerando a média nacional e a média da região em que o Estado se situa, a fim de verificar o desempenho que o Estado conseguiu com referência às médias regional e nacional. Esses dados são apresentados na Tabela 3. 
Tabela 3 - Classificação Geral dos Estados, de acordo com o IFGF, obtido no período de 2011 a 2015

\begin{tabular}{|c|c|c|c|c|c|}
\hline \multirow{2}{*}{ Posição } & \multirow{2}{*}{ Estado } & \multirow{2}{*}{ IFGF Geral } & \multicolumn{2}{|c|}{ Grupo de Referência } & \multirow{2}{*}{$\begin{array}{l}\text { Con- } \\
\text { ceito }\end{array}$} \\
\hline & & & Regional & Nacional & \\
\hline $1^{\circ}$ & Espírito Santo & 0,7004 & 1,3589 & 1,3791 & B \\
\hline $2^{\circ}$ & Roraima & 0,6602 & 1,2339 & 1,3001 & B \\
\hline $3^{\circ}$ & Distrito Federal & 0,5992 & 1,2210 & 1,1800 & C \\
\hline $4^{\circ}$ & Ceará & 0,5810 & 1,1663 & 1,1441 & C \\
\hline $5^{\circ}$ & Santa Catarina & 0,5775 & 1,1882 & 1,1372 & C \\
\hline $6^{\circ}$ & Pará & 0,5690 & 1,0635 & 1,1205 & C \\
\hline $7^{\circ}$ & Amazonas & 0,5646 & 1,0553 & 1,1118 & C \\
\hline $8^{\circ}$ & Pernambuco & 0,5294 & 1,0627 & 1,0424 & C \\
\hline $9^{\circ}$ & Rondônia & 0,5257 & 0,9825 & 1,0351 & C \\
\hline $10^{\circ}$ & Paraíba & 0,5168 & 1,0375 & 1,0177 & $\mathrm{C}$ \\
\hline $11^{\circ}$ & Amapá & 0,5159 & 0,9642 & 1,0159 & C \\
\hline $12^{\circ}$ & Rio Grande do Norte & 0,5014 & 1,0065 & 0,9872 & C \\
\hline $13^{\circ}$ & Mato Grosso do Sul & 0,5012 & 1,0212 & 0,9870 & C \\
\hline $14^{\circ}$ & Rio de Janeiro & 0,5000 & 0,9702 & 0,9846 & C \\
\hline $15^{\circ}$ & Bahia & 0,4995 & 1,0027 & 0,9836 & C \\
\hline $16^{\circ}$ & Piauí & 0,4977 & 0,9991 & 0,9800 & C \\
\hline $17^{\circ}$ & Paraná & 0,4950 & 1,0186 & 0,9748 & C \\
\hline $18^{\circ}$ & Maranhão & 0,4759 & 0,9554 & 0,9372 & C \\
\hline $19^{\circ}$ & Tocantins & 0,4712 & 0,8807 & 0,9279 & C \\
\hline $20^{\circ}$ & Sergipe & 0,4644 & 0,9322 & 0,9144 & C \\
\hline $21^{\circ}$ & São Paulo & 0,4626 & 0,8975 & 0,9109 & C \\
\hline $22^{\circ}$ & Mato Grosso & 0,4588 & 0,9348 & 0,9035 & C \\
\hline $23^{\circ}$ & Acre & 0,4387 & 0,8199 & 0,8638 & C \\
\hline $24^{\circ}$ & Alagoas & 0,4172 & 0,8376 & 0,8216 & C \\
\hline $25^{\circ}$ & Goiás & 0,4039 & 0,8230 & 0,7954 & C \\
\hline $26^{\circ}$ & Minas Gerais & 0,3986 & 0,7734 & 0,7849 & $\mathrm{D}$ \\
\hline $27^{\circ}$ & Rio Grande do Sul & 0,3855 & 0,7932 & 0,7592 & $\mathrm{D}$ \\
\hline
\end{tabular}

Elaborado pelos autores (2017).

Os resultados demonstram que apenas dois Estados se enquadraram no conceito B (Boa Gestão). O Espírito Santo, devido aos bons resultados obtidos nos índices Receita Própria, Gastos com Pessoal, Liquidez e Custo de Dívida; e Roraima, justificado pelos bons resultados obtidos nos índices de Liquidez, Custo da Dívida e Investimentos.

O Espírito Santo obteve um IFGF geral bastante expressivo, superando em 37,91\% a média nacional, e mostrando-se 35,89\% superior à média da Região Sudeste. Roraima obteve a melhor média da Região Norte, mostrando-se superior em 30\% sobre a média nacional, e 23,39\% sobre sua média regional. O campeão do Centro-Oeste foi o Distrito Federal, que obteve um IFGF final 22,10\% maior que a média da região, enquanto que no Nordeste o índice mais alto foi do Ceará, que se mostrou 16,63\% superior à média da região. No Sul do país, o Estado com melhor Gestão Fiscal foi Santa Catarina, superando em $18,82 \%$ a média sulista.

Ao todo, 23 (vinte e três) Estados foram classificados no conceito C (Gestão em Dificuldade), o que corresponde a $85,2 \%$ da amostra. Esse cenário de dificuldade já era assinalado por Sena (2012), quando evidenciou que $90 \%$ das entidades governamentais estudadas apresentaram gestões difícil ou crítica. Uma síntese dos resultados encontrados nesta 
pesquisa está apresentada no Gráfico 1.

Gráfico 1 - Qualidade da Gestão Fiscal dos Estados brasileiros, no período de 2011 a 2015
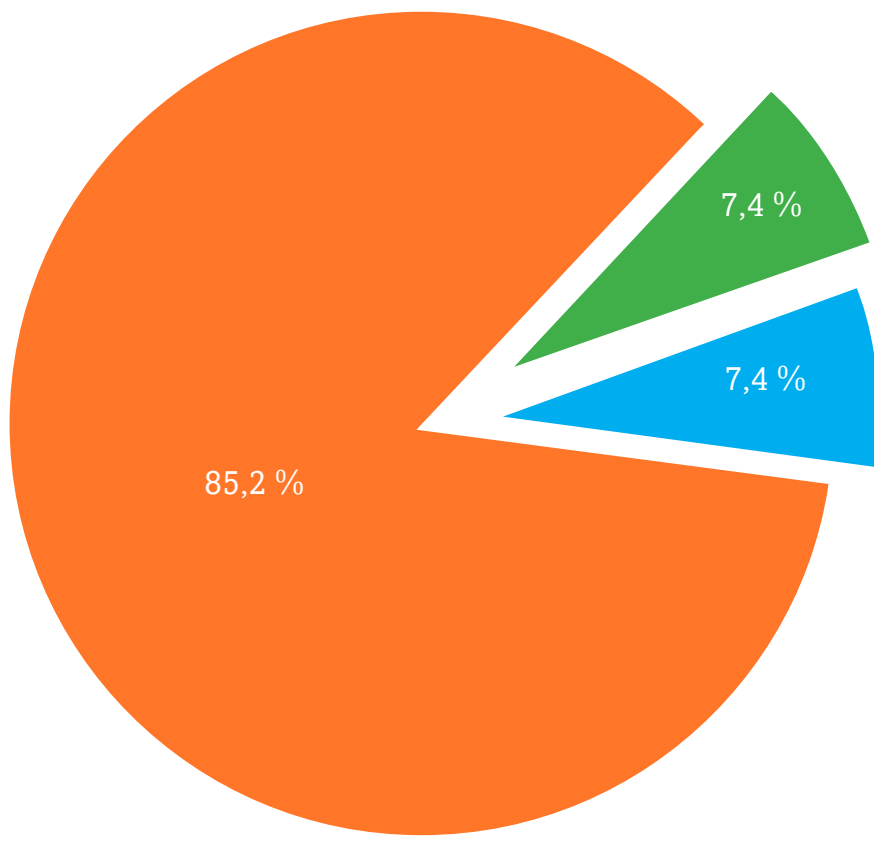

$\square$ Conceito B (Boa) $\backsim$ Conceito C (Dificuldade) $\square$ Conceito D (Crítica)

Fonte: Elaborado pelos autores (2017).

Outros dois Estados foram classificados no conceito D (Gestão Crítica), são eles: Minas Gerais e Rio Grande do Sul, que obtiveram médias, respectivamente, $21,51 \%$ e $24,08 \%$ inferior à média nacional. Pesaram para ambos os Estados os péssimos índices de Liquidez, Custo da Dívida e Investimentos.

Entre as regiões, a Norte foi a que obteve a melhor média durante o período, ainda que todas as regiões tenham apresentado média que se enquadra no conceito C (Gestão em Dificuldade), conforme exposto no Tabela 4.

Tabela 4 - Ranking final IFGF dos Estados brasileiros, segmentados por regiões

\begin{tabular}{ccccccc}
\hline IFGF & Norte & Sudeste & Nordeste & Centro-Oeste & Sul & Média Nacional \\
\hline Geral & 0,5351 & 0,5154 & 0,4981 & 0,4908 & 0,4860 & 0,5078 \\
Classificação & $1^{\circ}$ & $2^{\circ}$ & $3^{\circ}$ & $4^{\circ}$ & $5^{\circ}$ & \\
\hline
\end{tabular}

Fonte: Elaborado pelos autores (2017).

A Região Norte demonstrou o melhor desempenho fiscal no período analisado, mesmo sendo a região menos geradora de receitas próprias; houve certa preocupação por parte das gestões estaduais em fazer mais investimentos, ao mesmo tempo em que se endividava melhor, comprometendo uma quantidade menor de recursos para amortizar dívidas e, consequentemente, não prejudicando a sua disponibilidade de caixa.

Por outro lado, o que pesou para a Região Sul ser a última colocada foi o caminho inverso: a grande quantidade de recursos utilizados para pagamento da Dívida, que resultou na baixa realização de investimentos no período, assinalando ser um ponto bastante negativo na medida em que se cortam investimentos que possibilitam o crescimento e o bem-estar social, destinando-os à liquidação de dívidas de anos anteriores. Estes resultados são contrários aos de Souza Junior e Gasparini (2006), quando identificaram, na ocasião, que os estados situados na região Sul apresentavam situações fiscais melhores se comparados aos da região Nordeste.

Adicionalmente, foram estipuladas duas hipóteses de pesquisa que, concomitantemente às análises dos indicadores, puderam ser verificadas. Para isso, foram utilizados testes de correlação para identificar as relações bivariadas entre as variáveis. Como os dados não são contínuos, o recomendável pela literatura é que sejam utilizadas as correlações de Spearman. Mesmo assim, apresenta-se, na Tabela 5, a matriz de correlação de Pearson e Spearman entre as variáveis. 
Tabela 5 - Matriz de Correlação de Pearson e Spearman com os indicadores base do IFGF dos Estados brasileiros, no período de 2011 a 2015

\begin{tabular}{|c|c|c|c|c|c|c|}
\hline & IFGF Geral & RecProp & GPess & Liquidez & CustDivida & Investim \\
\hline \multirow[t]{2}{*}{ IFGF Geral } & & -0.0225 & $0.2523^{\star \star}$ & $0.5677^{\star \star \star \star}$ & $0.6594^{\star \star \star}$ & $0.3513^{* \star *}$ \\
\hline & & 0.7957 & 0.0032 & 0.0000 & 0.0000 & 0.0000 \\
\hline \multirow[t]{2}{*}{ RecProp } & -0.0222 & & 0.0479 & $-0.1904^{\star \star}$ & -0.1066 & -0.0936 \\
\hline & 0.7979 & & 0.5810 & 0.0270 & 0.2184 & 0.2800 \\
\hline \multirow[t]{2}{*}{ GPess } & $0.3424^{\star \star \star}$ & 0.0716 & & -0.0445 & -0.0945 & $0.2471^{\star \star \star *}$ \\
\hline & 0.000 & 0.4095 & & 0.6068 & 0.2758 & 0.0039 \\
\hline \multirow[t]{2}{*}{ Liquidez } & $0.5763^{\star \star \star}$ & $-0.2821^{\star \star \star}$ & -0.0797 & & 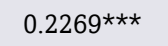 & $0.2583^{* \star *}$ \\
\hline & 0.000 & 0.0009 & 0.3581 & & 0.0081 & 0.0025 \\
\hline \multirow[t]{2}{*}{ CustDivida } & $0.6469^{\star \star \star}$ & -0.0728 & -0.0772 & 0.0403 & & 0.0348 \\
\hline & 0.000 & 0.4016 & 0.3732 & 0.6423 & & 0.6889 \\
\hline \multirow[t]{2}{*}{ Investim } & $0.3125^{\star \star \star}$ & -0.1274 & $0.2233^{\star * *}$ & 0.0072 & -0.0018 & \\
\hline & 0.000 & 0.1410 & 0.0092 & 0.9343 & 0.9836 & \\
\hline
\end{tabular}

Notas: RecProp corresponde a Receitas Próprias; GPess corresponde ao Gasto com Pessoal; CustDivida corresponde ao Custo da Dívida; Investim corresponde ao Investimento; os asteriscos indicam os níveis de significância: ${ }^{\star *} p<0,01 ;{ }^{* *}<0,05 ;{ }^{*} p<0,10$.

Fonte: Resultados da Pesquisa (2017).

Com relação à significância das correlações, observa-se que tanto Pearson como Spearman não apresentaram diferenças, indicando que o Custo da Dívida, a Liquidez, os Investimentos e o Gasto com Pessoal, nessa ordem, relacionam-se positivamente na gestão fiscal dos estados brasileiros. Apenas o indicador Receita Própria parece não apresentar relação forte na gestão fiscal dos estados brasileiros.

Dadas essas constatações, a segunda hipótese desta pesquisa que afirma que 'Entes governamentais que apresentam dívidas boas apresentam bons índices fiscais' foi aceita estatisticamente ao nível de $1 \%$, tendo em vista que o custo da dívida foi o indicador que apresentou maior relação positiva no cálculo IFGF $(0,6594)$ e, ainda, na liquidez $(0,2269)$ dos governos estaduais.

Com relação à hipótese 1, que levantou a ideia de que 'Entes Governamentais que apresentam menores gastos com pessoal conseguem realizar mais investimentos', esta foi aceita estatisticamente ao nível de $1 \%$, tendo em vista a correlação de Spearman observada entre as variáveis Gasto com Pessoal e Investimentos (0,2471).

Em síntese, como resposta ao objetivo proposto por essa investigação, conseguiu-se chegar à resposta de que a situação da gestão fiscal dos estados brasileiros é pouco satisfatória, tendo em vista os resultados negativos apresentados na maioria dos estados e em quase todos os anos, demonstrando que os gestores públicos devem buscar técnicas de aperfeiçoamento da gestão governamental brasileira.

\section{CONSIDERAÇÕES FINAIS}

Esta pesquisa teve como objetivo analisar a qualidade da Gestão Fiscal nos Estados Brasileiros durante o quinquênio de 2011 a 2015 e identificar as principais variáveis que afetam a gestão fiscal dos entes subnacionais, por meio da coleta de informações contábeis na base de dados FINBRA da STN, Portais Compara Brasil e Relatórios fornecidos pelos Governos.

Para mensurar isto, adotou-se a Metodologia desenvolvida pela FIRJAN, fazendo-se algumas adaptações visando evitar possíveis distorções na obtenção do resultado final e adequar a metodologia que fora desenvolvida para os Municípios, para o mais próximo possível da realidade econômica e financeira dos Estados. Adicionalmente, foram criados Rankings entre Estados e Regiões a fim de realizar comparações.

Mediante uma análise detalhada dos índices calculados - Receita Própria, Liquidez, Gastos com Pessoal, Investimento e Custo da Dívida - este trabalho se justificou pelo fato de possibilitar aos gestores dos Governos Estaduais maior compreensibilidade no gerenciamento dos recursos públicos, na medida em que faz uso desses índices como ferramenta de gestão e autoavaliação e, simultaneamente, esclarecer à sociedade sobre o melhor entendimento entre 
esses indicadores.

Os principais resultados indicaram que todos os Estados são capazes de gerar, em montantes satisfatórios, as receitas que lhes foram atribuídas no pacto federativo, via arrecadação tributária, principalmente os das regiões Sul e Sudeste, o que preconiza um aspecto favorável para boa condição financeira governamental.

Todavia, o elevado grau de Endividamento e, consequentemente, o elevado custo com os serviços da dívida impactam negativamente o fluxo de caixa dos Governos Estaduais, afetando diretamente a sua Liquidez, na medida em que as despesas são postergadas, haja vista a insuficiência de caixa gerada pelo desembolso com juros e amortizações da Dívida, proporcionando uma redução considerável na sua capacidade de realização de investimentos, principalmente com recursos próprios, demonstrando que a situação fiscal dos estados brasileiros não é satisfatória.

Estes resultados são aderentes à Teoria da Condição Financeira Governamental, quando pressupõe que entidades governamentais devem contrair boas dívidas, para não prejudicar os exercícios futuros consumindo os recursos disponíveis, prejudicando a liquidez governamental. Ademais, conforme Lima e Diniz (2016), a teoria diz que, quando as entidades governamentais apresentam gastos elevados com pessoal, reduzem a capacidade de investimentos.

Além disso, este estudo constatou o cenário preocupante em que se encontram os estados brasileiros, quando a média geral do IFGF durante o período foi de 0,5078, sendo classificada dentro do Conceito C (Gestão em Dificuldade), assinalando a necessidade de melhoria da gestão fiscal dessas entidades. Entre as regiões, observou-se que a Norte apresentou o melhor indicador fiscal, seguida pelas regiões Sudeste, Nordeste, Centro-Oeste e, por último, a Sul. Esses resultados são contrários aos identificados por Souza Junior e Gasparini (2006), que haviam evidenciado que a região Sul apresentava bons indicadores, enquanto a Norte, péssimos indicadores.

Quanto às hipóteses de pesquisa, ambas foram confirmadas estatisticamente ao nível de 1\%, revelando que à medida que o gestor consegue contrair boas dívidas, alcançará bons indicadores fiscais, não desequilibrando os orçamentos futuros e em benefício social, o que vem a confirmar os pressupostos da Teoria da Condição Financeira Governamental. Além disso, confirmou-se que os governos subnacionais que gastam menos com pessoal conseguem destinar maior parcela do seu orçamento para os investimentos, permitindo, possivelmente, a expansão dos serviços governamentais em prol da comunidade.

Recomenda-se, para estudos posteriores, que sejam realizadas outras pesquisas abrangendo um período maior e com outras variáveis, de modo a confirmar os resultados apresentados neste estudo.

Vale ressaltar que os resultados obtidos neste trabalho são limitados quanto ao período e à metodologia aplicada, pois podem variar com a análise de outro período ou a aplicação de metodologia diferente desta.

\section{REFERÊNCIAS}

ARAÚJO, Anderson Henrique dos Santos; SANTOS FILHO, José Emilio dos; GOMES, Fábio Guedes. Lei de Responsabilidade Fiscal: efeitos e consequências sobre os municípios alagoanos no período 2000-10. Revista de Administração Pública - RAP, v. 49, n. 3, 2015.

AZEVEDO, Ezequiel Diniz. Indicadores contábeis de desempenho orçamentário e o indice FIRJAN de desenvolvimento municipal (IFDM) da saúde e educação: estudo nos municipios mais populosos por região brasileira. Trabalho de Conclusão de Curso (Monografia) Curso de Ciências Contábeis Universidade Federal do Rio Grande do Norte, Natal, 2016.

BEUREN, Ilze Maria. Como Elaborar Trabalhos Monográficos em Contabilidade. 3. ed. São Paulo: Atlas, 2008.

BEZERRA FILHO, João Eudes. Contabilidade Aplicada ao Setor Público. 2. ed. São Paulo: Atlas, 2015.

BRASIL. Constituição da República Federativa do Brasil, de 05 de outubro de 1988. Brasília, DF.

. Lei Complementar $n^{\circ}$. 101, de 04 de Maio de 2000. Estabelece normas de finanças públicas voltadas para a responsabilidade na gestão fiscal e dá outras providências. Diário Oficial [da] República Federativa do Brasil. Brasília, DF, 05 maio 2000.

Lei $n^{\circ}$. 4.320, de 17 de março de 1964. Dispõe sobre normas gerais de direito financeiro para elaboração e controle dos orçamentos e balanços da União, Estados, Municípios e Distrito Federal. Diário Oficial [da] República Federativa do Brasil. Brasília, DF, 23 março1964.

Lei $\mathrm{n}^{\circ}$. 12.527, de 18 de novembro de 2011. Regula o acesso a informações previsto no inciso XXXIII do art. $5^{\circ}$, no inciso

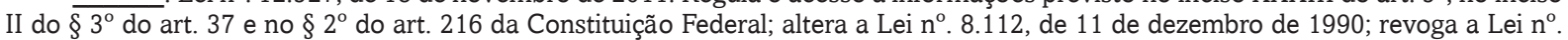
11.111, de 5 de maio de 2005, e dispositivos da Lei n. 8.159, de 8 de janeiro de 1991; e dá outras providências. Diário Oficial [da] República Federativa do Brasil. Brasília, DF, 18 nov. 2011 - edição extra.

BRASIL. SENADO FEDERAL. Resolução $n^{\circ}$. 43, de 21 de dezembro de 2001. Dispõe sobre as operações de crédito interno e externo dos Estados, do Distrito Federal e dos Municípios, inclusive concessão de garantias, seus limites e condições de autorização, e dá outras providências. Diário Oficial [da] República Federativa do Brasil, Poder Legislativo, Brasília, DF, 26 dez. 2001, Seção 1, p. 1. Republicado Diário Oficial da República Federativa do Brasil, Poder Legislativo, Brasília, DF, 10 abril 2002.

CORREIA, Fernando Motta. Finanças Públicas Estaduais: uma breve análise do impacto da Lei de Responsabilidade Fiscal sobre alguns indicadores orçamentários LRF-Gastos Públicos-Estados brasileiros. Revista Economia \& Tecnologia, v. 10, n. 2, 2014.

COSTA, André Ricardo Reis; ARAÚJO, João Tiago Souza de; ALVES, Adenes Teixeira; SANTOS, Carla Macedo Velloso dos. Análise dos fatores determinantes da evolução da dívida do município de Manaus, no período de 2010 a 2015. Gestão Pública: Práticas e Desafios v. 10, n. 2, 2017.

COSTA, Walter Luiz. Contribuição à metodologia de apuração do resultado fiscal nos estados brasileiros: um estudo empírico de 2008 a 2015. Dissertação de Mestrado do Programa de Pós-Graduação da FUCAPE, Vitória (ES), 2016. 
DALMONECH, L. F; TEXEIRA, A.; SANT’ANA, J. M. B. O impacto ex-post da Lei de Responsabilidade Fiscal nº 101/2000 nas finanças dos estados brasileiros. Rev. Adm. Pública Rio de Janeiro, vol. 45, n. 4, jul./ago. 2011.

FEDERAÇÃO DAS INDÚSTRIAS DO ESTADO DO RIO DE JANEIRO (FIRJAN). Anexo Metodológico Índice Firjan de Gestão Fiscal - Ano Base 2015. 2015.

GIACOMONI, James. Orçamento Público. 16. ed. São Paulo: Atlas, 2012.

GIUBERTI, Ana Carolina. Efeitos da lei de responsabilidade fiscal sobre os gastos dos municipios brasileiros. Tese de Doutorado. Universidade de São Paulo, São Paulo (SP), 2005.

GROVES, S. M.; VALENTE, M. G. Evaluating financial condition: a handbook for local government. 4th ed. Revised by Karl Nollenberger. Washington: The International City/County Management Association - ICMA, 2003. Paulo, 2015

INSTITUTO BRASILEIRO DE PLANEJAMENTO E TRIBUTAÇÃO (IBPT). Estudo Comemorativo 10 anos do Impostômetro. São 2016.

LIMA, Severino Cesário; DINIZ, Josedilton Alves. Contabilidade Pública: Análise Financeira Governamental. São Paulo: Atlas,

NAKAGUMA, Marcos Yamada; BENDER, Siegfied. A emenda da reeleição e a Lei de Responsabilidade Fiscal: impactos sobre ciclos políticos e performance fiscal dos Estados (1986-2002). Economia aplicada, v. 10 (3), p. 377-397, 2006.

RIBEIRO, Márcio Bruno. Desempenho e eficiência do gasto público: uma análise comparativa entre o Brasil e um conjunto de países da América Latina. Rio de Janeiro: IPEA, 2008. Disponível em: <http://www.ipea.gov.br/portal/index.php?option=com_content\&view $=$ article\&id=4920.> Acesso em: 10 nov.2016.

ROCHA, Arlindo Carvalho. Accountability na administração pública: modelos teóricos e abordagens. Contabilidade, Gestão e Governança, v. 14 (2), p. 82-97, 2011.

SALES, Tainah Simões; MARTINS, Ana Laís Pinto. Planejamento, transparência, controle social e responsabilidade na administração pública após o advento da lei de responsabilidade fiscal. Nomos, v. 34, n. 1, 2014.

SALGUEIRO, M. A. de A.; MELO, C. B.; SILVA, D. S. A Dívida Pública dos Estados Brasileiros: um estudo sobre o impacto dos encargos da dívida antes e depois da aprovação da Lei de Responsabilidade Fiscal - LRF. 2012. Convibra. Disponível em: <http://www. convibra.com.br/upload/paper/2014/38/2014_38_10629.pdf>. Acesso em: 15 nov. 2016.

SECRETARIA DO TESOURO NACIONAL (STN). Manual de Contabilidade Aplicada ao Setor Público. 6. ed. 2014.

SENA, Bruno Torquato. Índice de gestão fiscal dos municípios: Análise do IGF de Vinte Municípios do RN no Exercício 2010. Monografia (Trabalho de Conclusão de Curso) Graduação em Ciências Contábeis, Universidade Federal do Rio Grande do Norte. Natal (RN), 2012.

SILVA, Anderson Caputo; CARVALHO, Lena Oliveira; MEDEIROS, Otavio Ladeira. (Org.) Divida Pública: A experiência brasileira. Brasília: Secretaria do Tesouro Nacional: Banco Mundial, 2009.

SILVA, Tainan Carlos Correia; LIMA, Diana. A adoção do princípio da competência no tratamento contábil dos restos a pagar. In: Congresso USP de Controladoria e Contabilidade, 10, 2016, São Paulo, Anais... São Paulo, 2016.

SOUSA, Francisco Hélio. O caráter impositivo da lei orçamentária anual e seus efeitos no sistema de planejamento orçamentário, 2008. Disponivel em: <http://www3.tesouro.fazenda.gov.br/Premio_TN/XIIIPremio/sistemas/2tosiXIIIPTN/Carater_Impositivo_Lei_Orcamentaria.pdf> Acesso em: 5 nov. 2016.

SOUZA JUNIOR, Celso Vila Nova; GASPARINI, Carlos Eduardo. Análise da equidade e da eficiência dos estados no contexto do federalismo fiscal brasileiro. Estudos Econômicos, v. 36(4), out./dez. 2006. 